$10-2005$

\title{
Association Between Lower Extremity Posture at Contact and Peak Knee Valgus Moment During Sidestepping: Implications for ACL Injury
}

Scott G. McLean

Cleveland Clinic Foundation, mcleans@ccf.org

Xuemei M. Huang

Cleveland Clinic Foundation

Antonie J. van den Bogert

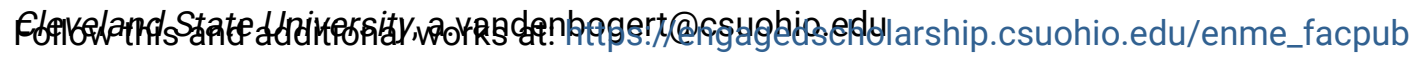

Part of the Biomechanical Engineering Commons

How does access to this work benefit you? Let us know!

\section{Publisher's Statement}

NOTICE: this is the author's version of a work that was accepted for publication in Clinical Biomechanics. Changes resulting from the publishing process, such as peer review, editing, corrections, structural formatting, and other quality control mechanisms may not be reflected in this document. Changes may have been made to this work since it was submitted for publication. A definitive version was subsequently published in Clinical Biomechanics, 20, 8, (10-01-2005); 10.1016/j.clinbiomech.2005.05.007

\section{Original Citation}

McLean, S. G., Huang, X., and van den Bogert, A., 2005, "Association between Lower Extremity Posture at Contact and Peak Knee Valgus Moment during Sidestepping: Implications for ACL Injury," Clinical Biomechanics, 20(8) pp. 863-870.

This Article is brought to you for free and open access by the Mechanical Engineering Department at EngagedScholarship@CSU. It has been accepted for inclusion in Mechanical Engineering Faculty Publications by an authorized administrator of EngagedScholarship@CSU. For more information, please contact library.es@csuohio.edu. 


\title{
Association between lower extremity posture at contact and peak knee valgus moment during sidestepping: Implications for ACL injury
}

\author{
Scott G. McLean *, Xuemei Huang, Antonie J. van den Bogert \\ Department of Biomedical Engineering, The Cleveland Clinic Foundation, 9500 Euclid Ave, Cleveland, OH 44195, USA
}

\section{Introduction}

Anterior cruciate ligament (ACL) injury is a common and traumatic knee joint injury. Approximately 100,000 ACL injuries occur annually within the United States (Frank and Jackson, 1997) with the majority of these suffered by young healthy individuals. Approximately $70 \%$

\footnotetext{
- Corresponding author.

E-mail address: mcleans@ccf.org (S.G. McLean).
}

of ACL injuries occur via a non-contact episode, typically during execution of jump-landing, pivoting or cutting movements (Agel et al., 2005). The well-documented increase in sports-related ACL injury rates occurring in females compared to males is particularly disturbing (Arendt and Dick, 1995; Griffin et al., 2000). Established links between ACL injury and osteoarthritis (Maletius and Messner, 1999) further compound this problem, suggesting that a large number of female and male athletes will incur significant knee joint degeneration at a relatively young age. A reduction in sports participation is 
obviously not the solution to reducing ACL injury rates. Rather, effective prevention through an understanding of the underlying causal factors is essential.

Abnormal or altered neuromuscular control in women during sports movements is viewed as a primary extrinsic contributor to their increased risk of ACL injury compared to males (Griffin et al., 2000; Ireland, 2002). Neuromuscular control effects during these movements, such as that stemming from altered muscular strength, recruitment and timing, manifest and are clearly evident within subsequent joint motions and loads (Griffin et al., 2000; Hewett et al., 2005; Huston and Wojtys, 1996; Lephart et al., 2002). As a result, gender differences in these parameters have been evaluated extensively to identify potential underlying neuromuscular mechanisms of sports-related ACL injury (Chappell et al., 2002; Decker et al., 2003; Ferber et al., 2003). Recently, Hewett et al. (2005) has shown prospectively, that a larger knee valgus moment during jump-landing tasks predicts ACL injury risk in young female athletes. Females are also known to exhibit larger knee valgus loads than males during similar movements (Chappell et al., 2002). Minimizing knee valgus moments during sports movements therefore, appears crucial to the prevention of ACL injuries, particularly in women.

Recent studies have shown that training programs focusing on successful modification of altered or abnormal joint motions may reduce the risk of ACL injury (Hewett et al., 1996, 1999; Myklebust et al., 2003; Olsen et al., 2005). Despite these programs continuing to grow both in number and complexity however, ACL injury rates and in particular the gender disparity in these rates, have remained constant (Agel et al., 2005). The ultimate success of these programs may currently be limited by a lack of knowledge pertaining to which joint postures are indeed high-risk. It is increasingly recognized that extreme knee loading scenarios may stem from abnormal joint motions beyond the knee joint (Ireland, 2002; McLean et al., 2004a; Zeller et al., 2003). Stance phase valgus loading during sidestepping movements was shown in a computational model for example, to be particularly sensitive to lower limb postures at initial contact (McLean et al., 2003, 2004b). With this in mind, determining associations between initial contact joint postures and valgus loading, especially those amenable to targeted intervention would afford more effective prevention of non-contact ACL injuries in the future. Furthermore, identifying the extent to which such associations are dependent on gender may reduce the current disparity in ACL injuries between men and women.

The primary purpose of the current study therefore, was to evaluate the relationship between lower limb joint posture at initial contact during sidestepping and the subsequent peak valgus moment. A second purpose was to examine the potential for gender specificity in these relationships.

\section{Methods}

\subsection{Subjects}

Twenty National Collegiate Athletic Association (NCAA) division I basketball players (10 males and 10 females) were recruited for the purpose of the current investigation. Prior to experimentation, approval for the research was gained through the Institutional Review Board of the Cleveland Clinic Foundation and written informed consent for all subjects was obtained. Subject inclusion in the study was based on no history of operable lower limb joint injury. A summary of subject characteristics is presented in Table 1 .

\subsection{Procedures}

For each subject, three-dimensional (3D) lower limb kinematic, and 3D ground reaction force data were recorded for the right (contact) leg during the execution of ten sidestep cutting maneuvers. A successful sidestep trial necessarily required the contact phase of the movement to occur in the center of a force plate (AMTI OR6-5 \#4048, Advanced Mechanical Technology Inc, Watertown, MA, USA), within the field of view of a six-camera high-speed (240 fps) motion analysis system (Motion Analysis Corp ${ }^{\circledR}$, Santa Rosa, Ca, USA). Approach speeds were required to fall between $4.5 \mathrm{~m} \mathrm{~s}^{-1}$ and $5.5 \mathrm{~m} \mathrm{~s}^{-1}$ (McLean et al., 2004a).

Cutting angles were required to be between $35^{\circ}$ and $55^{\circ}$ from the original direction of motion, with this range demarcated (with tape) by lines on the floor, originating at the center of the forceplate (Fig. 1). Subjects were required to continue running following sidestep execution for approximately five steps, with a trial deemed successful if the initial foot contact following the cutting action fell within this prescribed range.

\subsection{Data collection}

For each subject, nineteen reflective markers of diameter $24 \mathrm{~mm}$ were secured with strapping tape to predefined anatomical locations (Fig. 2). Attachment sites

Table 1

Characteristics of subjects included in the current investigation

\begin{tabular}{lcc}
\hline Characteristic & \multicolumn{2}{l}{ Gender } \\
\cline { 2 - 3 } & $\begin{array}{l}\text { Male }(\text { Mean }( \pm \mathrm{SD})) \\
(n=10)\end{array}$ & $\begin{array}{l}\text { Female }(\text { Mean }( \pm \mathrm{SD})) \\
(n=10)\end{array}$ \\
\hline Age (years) & $20.2(1.9)$ & $21.1(3.0)$ \\
Experience (years) & $10.2(5.1)$ & $10.5(4.8)$ \\
Height $(\mathrm{cm})$ & $184.7(8.0)$ & $176.0(11.1)$ \\
Mass $(\mathrm{kg})$ & $81.9(9.8)$ & $76.1(12.4)$ \\
Femur length $(\mathrm{cm})$ & $49.6(4.5)$ & $44.5(3.8)$ \\
Tibia length $(\mathrm{cm})$ & $41.7(3.6)$ & $39.2(3.6)$ \\
\hline
\end{tabular}




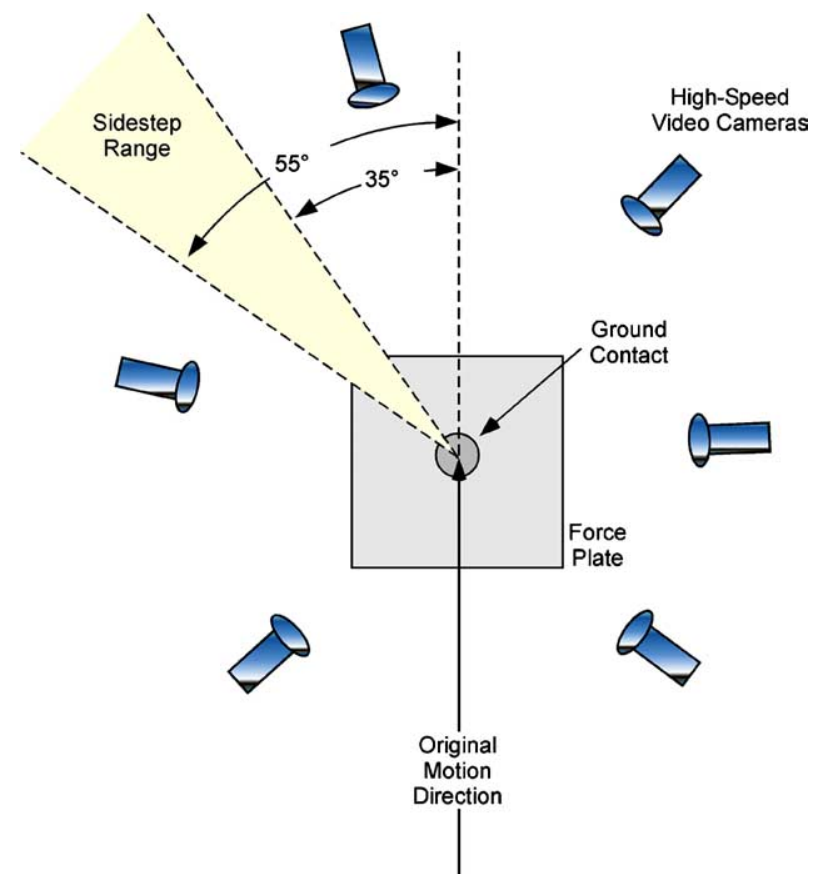

Fig. 1. Illustrations of movement criteria for a successful sidestep trial. Success was based on the stance phase occurring on a force plate, within the field of view of a high-speed video system.
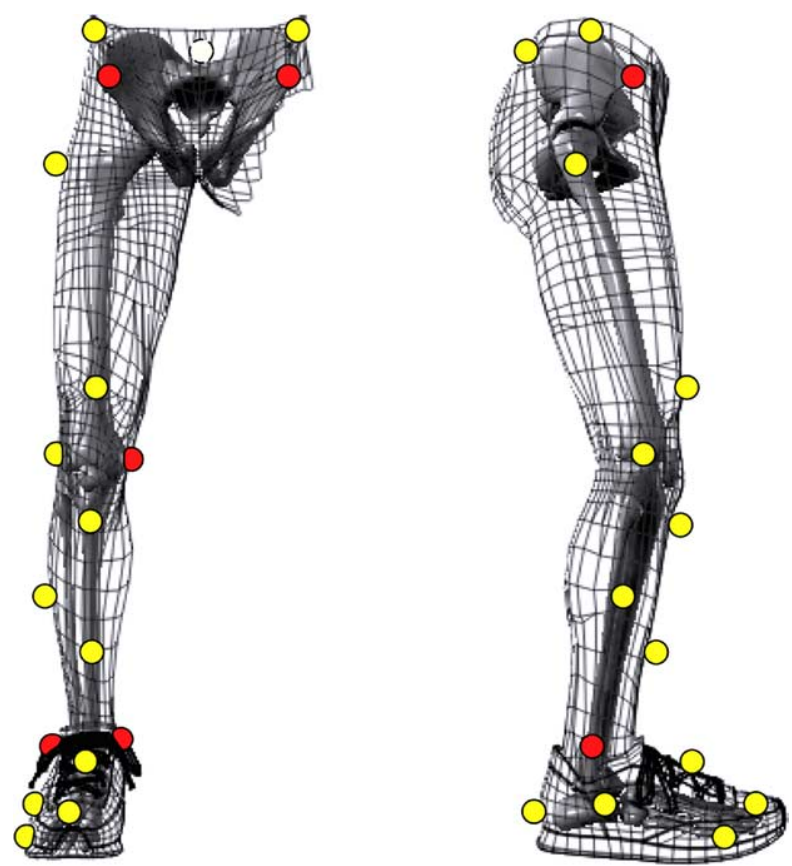

Fig. 2. Marker locations used to define a kinematic model comprised of five skeletal segments. The left and right ASIS, medial femoral condyle and lateral and medial malleoli markers (gray) were removed for the recording of movement trials.

were first shaved and attachment over areas of large muscle mass was avoided in order to reduce excessive marker movement. A static trial was initially recorded via the high-speed video system with the subject stand- ing in the neutral position (McLean et al., 2004a). The left and right anterior superior iliac spine (ASIS), medial femoral condyle and medial and lateral malleoli markers were then removed prior to the recoding of movement trials (see Fig. 2).

\subsection{Data analyses}

From the standing trial, a kinematic model was generated by defining five skeletal segments (foot, talus, shank and thigh of the support limb, and the pelvis) and 14 degrees of freedom (DoF) using Mocap Solver 6.17 (Motion Analysis Corp., Santa Rosa, California), as presented in detail previously (McLean et al., 2004a). The pelvis was assigned six DoF relative to the global (laboratory) coordinate system, with the hip, knee and ankle joints defined locally and assigned three, three and two rotational DoF, respectively (Fig. 3). The 3D marker trajectories recorded during each sidestepping trial were then processed by the Mocap Solver

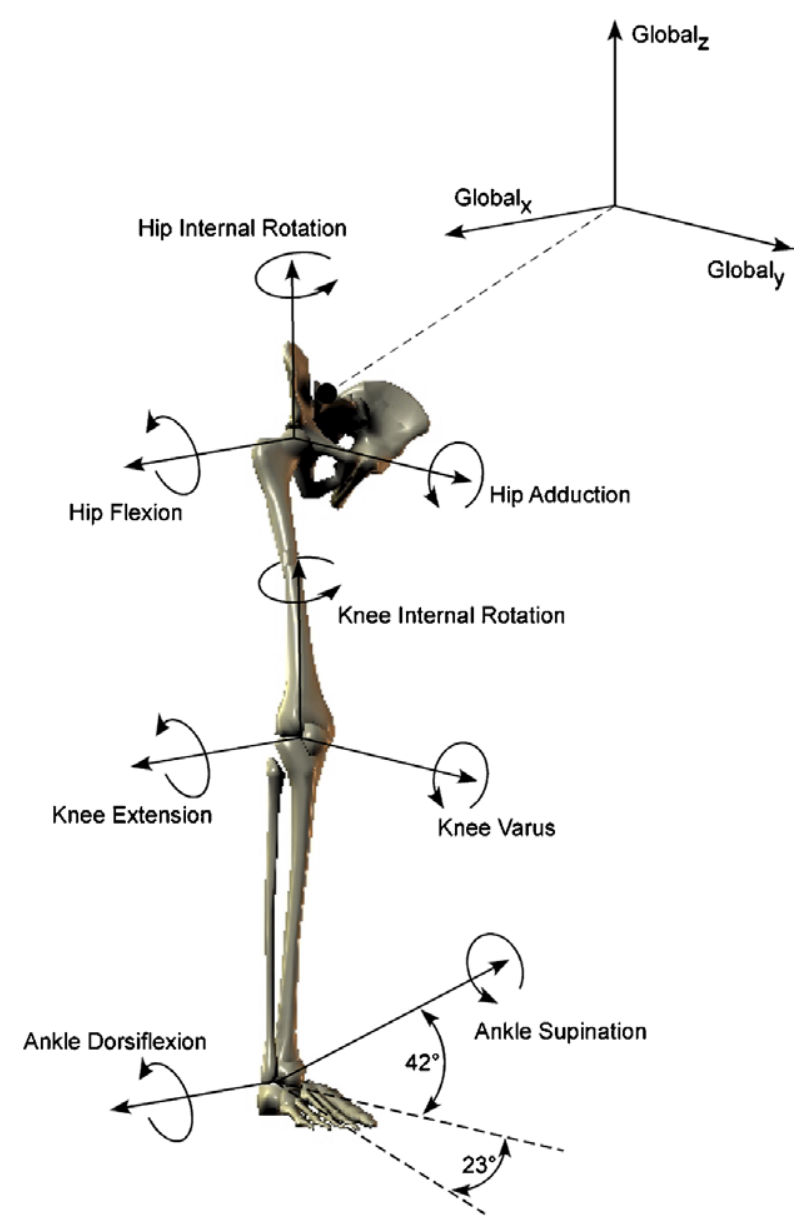

Fig. 3. For the kinematic model, pelvis (body) motion was described with respect to the global (lab) coordinate system via three translational and three rotational degrees of freedom. The hip, knee and ankle joints were defined locally and assigned three, three and two rotational DoF, respectively. 
software to solve for the fourteen DoF of the skeleton model at each time frame. These and the 3D ground reaction force (GRF) data were low-pass filtered with a cubic smoothing spline at an $18 \mathrm{~Hz}$ cut-off frequency (Woltring et al., 1985). For each trial, the velocity of the $X$ coordinate (direction of motion) of the greater trochanter marker was also calculated over the $103 \mathrm{D}$ video frames recorded prior to foot contact and was used to calculate approach velocity.

Three-dimensional intersegmental forces and moments were obtained by submitting the filtered kinematic and GRF data to a conventional inverse dynamics analysis (Winter, 2005). Segment inertial characteristics were defined in accordance the work of de Leva (1996). The 3D intersegmental force at the knee was transformed to the tibial reference frame to obtain anterior-posterior, medial lateral, and compression-distraction forces. Intersegmental moments were expressed as flexion-extension, varus-valgus and internal-external rotation moments with respect to the cardanic axes of the knee joint coordinate system (Grood and Suntay, 1983). Joint loads represented the external loads applied at the knee joint. For instance, the term "knee valgus moment" is used for an external load that acts to move the knee into a valgus posture. Kinetic data were timenormalized to $100 \%$ of stance, with heel strike and toe-off being defined as the instant when the vertical GRF first exceeded and went below $10 \mathrm{~N}$, respectively.

\subsection{Statistical treatment}

Hip $(n=3)$, knee $(n=3)$ and ankle $(n=2)$ angles exhibited at initial contact, and the resultant normalized (mass $\times$ height) peak stance phase knee valgus moment were determined for each trial. Normalized peak valgus moment data were submitted to a two-sample $t$-test to examine for the effect of gender. Intra-subject correlation coefficients between each of the eight initial joint angles and the normalized valgus moment were then computed across the ten sidestepping trials. The slopes $(n=8)$ of each subject's linear regressions were similarly submitted to a two-sample $t$-test to first determine whether mean slope values were significantly different from zero and for the main effect of gender. For all statistical analyses, an alpha level of $P=0.05$ was used to test for statistical significance.

\section{Results}

All subjects demonstrated a noticeable peak in stance phase knee valgus moment during sidestepping trials, with this peak typically occurring during the first $20 \%$ of stance. Normalized peak valgus moment was significantly $(P<0.05)$ larger in females $\left(0.63(0.20) \mathrm{N} \mathrm{m} \mathrm{kg}^{-1}\right.$ $\left.\mathrm{m}^{-1}\right)$ than in males $\left(0.42(0.11) \mathrm{N} \mathrm{m} \mathrm{kg}^{-1} \mathrm{~m}^{-1}\right)$ (Fig. 4).

Normalized peak valgus moment was correlated with initial contact hip flexion-extension, hip internal-external rotation and knee varus-valgus, with each correlation yielding a mean slope that was significantly $(P<0.05)$ different from zero (Table 2$)$. Specifically,

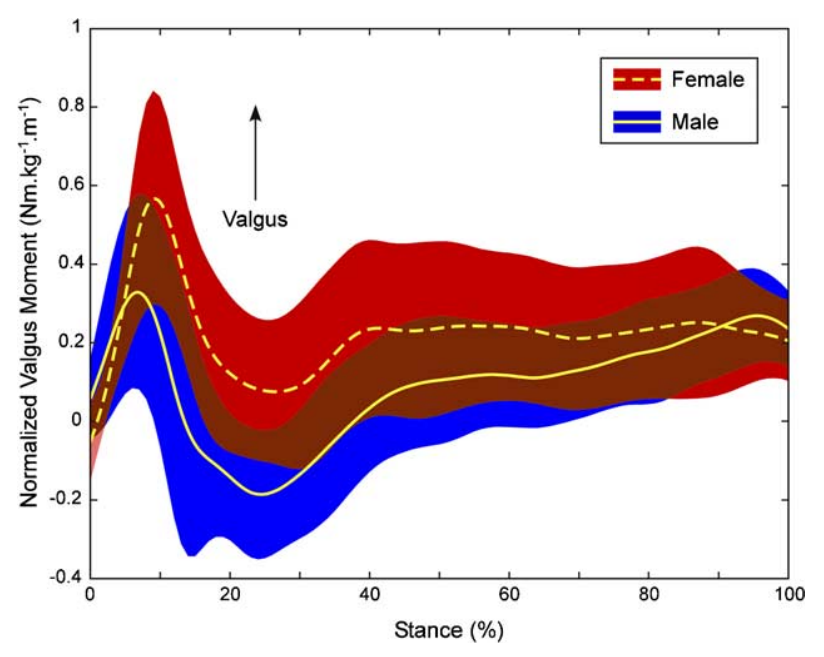

Fig. 4. Effect of gender on mean $( \pm \mathrm{SD})$ normalized (height $\times$ mass) external knee valgus moment demonstrated during sidestep stance.

Table 2

Gender comparisons of mean (SD) slope and $r^{2}$ values obtained for correlations between initial contact kinematic variables and normalized (mass $\times$ height) resultant peak stance phase knee valgus moment $\left(\mathrm{N} \mathrm{m} \mathrm{kg}^{-1} \mathrm{~m}^{-1}\right)$ during sidestep cutting maneuvers

\begin{tabular}{|c|c|c|c|c|}
\hline \multirow[t]{2}{*}{ Contact variable $\left({ }^{\circ}\right)$} & \multicolumn{2}{|l|}{ Male } & \multicolumn{2}{|l|}{ Female } \\
\hline & Slope & $r^{2}$ & Slope & $r^{2}$ \\
\hline Hip Flex/Ext ${ }^{\mathrm{a}}$ & $0.004(0.010)$ & $0.16(0.19)$ & $0.013(0.017)$ & $0.19(0.19)$ \\
\hline Hip ADd/ABd & $0.003(0.014)$ & $0.23(0.29)$ & $0.007(0.020)$ & $0.14(0.19)$ \\
\hline Hip Int/Ext rotation ${ }^{a, b}$ & $0.007(0.031)$ & $0.56(0.20)$ & $0.036(0.026)$ & $0.60(0.24)$ \\
\hline Knee Flex/Ext & $-0.006(0.021)$ & $0.21(0.23)$ & $-0.003(0.019)$ & $0.10(0.09)$ \\
\hline Knee Var/Valga,b & $-0.001(0.031)$ & $0.21(0.21)$ & $-0.067(0.046)$ & $0.35(0.17)$ \\
\hline Knee Int/Ext rotation & $0.001(0.016)$ & $0.27(0.28)$ & $0.014(0.026)$ & $0.26(0.27)$ \\
\hline Ankle PF/DF & $0.004(0.011)$ & $0.11(0.14)$ & $0.001(0.018)$ & $0.23(0.24)$ \\
\hline Ankle Inv/Ev & $-0.012(0.02)$ & $0.19(0.22)$ & $-0.008(0.024)$ & $0.23(0.25)$ \\
\hline
\end{tabular}

\footnotetext{
${ }^{a}$ Denotes slope significantly different from zero $(P<0.05)$.

${ }^{\mathrm{b}}$ Denotes slope significantly different between genders $(P<0.05)$.
} 


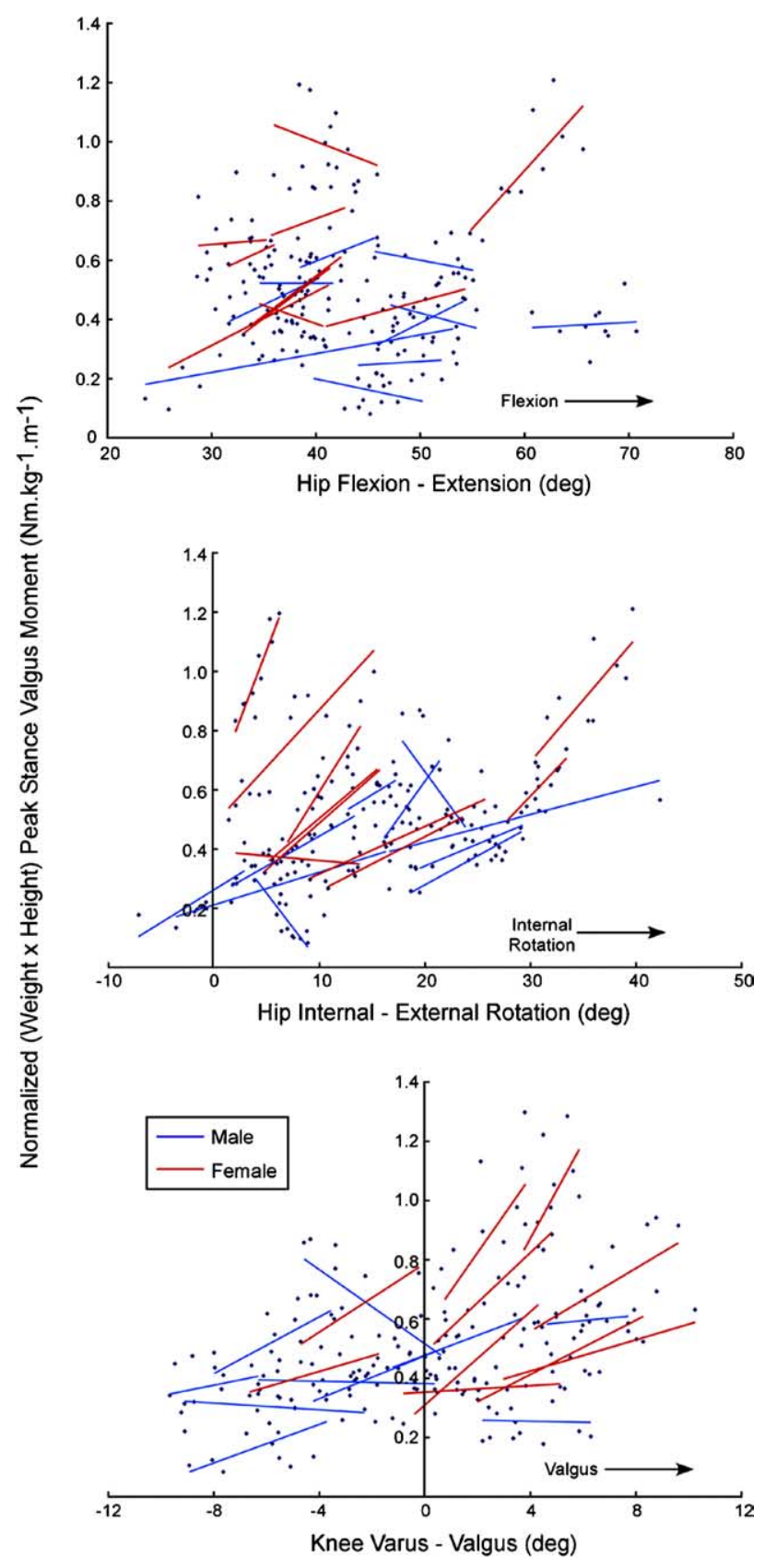

Fig. 5. Associations between peak knee valgus moment demonstrated during sidestep stance and isolated initial contact lower limb kinematic parameters (hip flexion-extension, hip internal-external rotation and knee varus-valgus) as a function of gender. Regression lines are calculated for each subject based on data obtained over ten sidestep cutting trials.

higher peak valgus loading was associated with higher initial hip flexion, hip internal rotation and knee valgus positions, respectively (Fig. 5).

Correlations between normalized peak valgus and both hip internal-external and knee varus-valgus rotations yielded mean slope values that were significantly greater in females compared to males. Thus for each case, peak valgus in females was significantly more sen- sitive to initial contact postures than in males, with small changes in these initial values resulting in relatively large changes in the valgus moment (see Table 2, Fig. 5).

\section{Discussion}

Effective prevention of non-contact ACL injuries relies on successful modification of at-risk lower limb biomechanics during sports movement execution (Hewett et al., 1999, 2005; Lephart et al., 2002). The current study examined the relationship between lower limb joint kinematics at initial contact during sidestepping movements and the subsequent peak knee valgus moment to elucidate potential associations between these factors and ACL injury risk.

Knee varus-valgus moment patterns observed during sidestep stance were consistent with those reported previously for the same movements (Besier et al., 2001). Valgus moment data in that study were reported for male subjects only, and were averaged over and reported for three discrete stance phase intervals, making direct comparisons to current data difficult. If we average our male data over the same approximate stance phase intervals however, we do see mean valgus moments of similar magnitudes to those reported by Besier et al. (2001), particularly during early stance. Worth noting is that average valgus moments for our female subjects appear to be much higher during this same early stance phase (see Fig. 4). This discrepancy between genders may an important contributor to ACL injury risk and is examined further below.

Females in the current study had significantly larger normalized peak valgus moments than males during the sidestepping movements. This result provides the first evidence of a gender difference in valgus loading for sidestep cutting, and is consistent with previous observations in other sport movements, such as running (Ferber et al., 2003) and jump-landing tasks (Chappell et al., 2002). It is also consistent with previous sidestep kinematic studies, in which females similarly had larger knee valgus motions (Malinzak et al., 2001; McLean et al., 2004a). Valgus loads and motions during lumplanding tasks have recently been shown prospectively to predict ACL injury risk in female athletes (Hewett et al., 2005). Although we do not have similar prospective data, it is possible that increased knee valgus during normal sidestepping movements may also be a predictor of ACL injury risk, with this risk being more pronounced in women.

Peak knee valgus moment was associated with initial contact hip flexion and internal rotation position during sidestep movements, with this association being particularly strong in the latter. Hip neuromuscular control has been suggested previously to influence resultant knee valgus motions and loads exhibited during single-leg squat 
(Zeller et al., 2003) and running tasks (Ferber et al., 2003). The association between isolated hip angles and valgus loading however was not investigated explicitly in either case. Selective activation of medial lower limb muscle groups has been observed previously for sidestepping tasks, as a means to counter the relatively large external valgus loads simultaneously applied to the knee joint (Besier et al., 2003; Lloyd and Buchanan, 2001; Zhang et al., 2001). Increased hip internal rotation and/or flexion at initial contact therefore, may compromise the ability of medial muscle groups to adequately support resultant knee valgus loads. We did not control for initial kinematic conditions during the current study and hence it is impossible to elucidate a cause and effect relationship between these variables and peak valgus moment. Forward dynamic simulations of sidestepping movements in which initial kinematic conditions can be selectively modified would provide further insight here (McLean et al., 2003, 2004b). Regardless however, there appears to be a direct link between peak valgus moment and hip flexion and internal rotation position during sidestepping. Further work is now necessary to precisely identify the underlying mechanism of such a link.

Valgus moment was more sensitive to changes in initial hip internal-external rotation angle in females, compared to males. Gender differences have been observed previously in hip and knee joint angles and loads for other dynamic movement tasks such as running (Ferber et al., 2003) and jump landing (Salci et al., 2004). Potential associations between these factors were, however, not investigated. Decreased hip muscle strength and endurance, and altered muscle activation timing and recruitment, such as increased quadriceps dominance, have been observed previously in females compared to males during dynamic movements (Huston and Wojtys, 1996; Ives et al., 1993; Zeller et al., 2003) and have been suggested to predispose females to various knee joint injuries (Ireland, 2002; Hutchinson and Ireland, 1995). It may be therefore, that women are required to land with more consistent hip motions compared to males during sidestepping to compensate for these neuromuscular differences. This idea appears further substantiated by recent findings that females have less hip internal-external rotation variability than males during sidestepping (McLean et al., 2004a). We did not currently assess muscle strength and/or recruitment patterns and hence the relationship between these parameters and valgus loading as a function of gender remains largely speculative.

It is worth noting that while statistically significant differences were observed in mean regression slope data between males and females, reasonable between-subject variations in these data were evident in both gender groups (see Fig. 5). Some males for instance, demonstrated valgus moments that also appeared particularly sensitive to initial contact hip rotation angles, and may thus similarly be at increased risk of potentially hazard- ous valgus moments. Conversely, some females appear to be at a decreased risk of such an event. If initial contact hip rotation posture is indeed associated with ACL injury risk via a valgus loading mechanism therefore, future screening for such associations should not simply be limited to females. Furthermore, neuromuscular training programs aimed at reducing ACL injury risk via such a mechanism appear well served to focus on enhancing lower limb muscular strength and control in both men and women, particularly at the hip.

The peak valgus moment during sidestepping was also found to be dependent on initial contact valgus angle. This causal link between initial valgus angle and subsequent valgus loading is somewhat intuitive, with an increased valgus angle precipitating an increased valgus moment arm of the GRF at contact. Assuming elastic ligamentous constraints, this would increase subsequent valgus alignment throughout weight bearing, acting in turn to further increase the valgus moment arm of the GRF. This vicious circle of events is similar to the beam buckling mechanism in mechanics and may explain why valgus loads were more sensitive to initial valgus position in females, who typically landed with greater knee valgus than the male subjects (see Fig. 5). The increased rotational knee joint laxity in women compared to men (Wojtys et al., 2003; Rozzi et al., 1999) might also be an important contributing factor to this mechanism. The current study did not investigate potential links between structural and neuromuscular factors. Such associations should be considered in future studies as ACL injury prevention may ultimately rely on neuromuscular control adaptations within non-modifiable anatomical constraints.

A potential limitation of this study was that initial contact joint angles were correlated with peak stance phase valgus moment for sidestep tasks performed within a relatively small cutting range. Restricting the cutting range in this fashion may have impacted on the degree of consistency in performing these movements and hence, the strength of these correlations for some subjects. Considering between-trial variations in initial joint angles varied considerably between subjects (see Fig. 5), this limitation appears possible. As noted earlier however, it may that some subjects must necessarily be more consistent in their initial contact joint postures due the increased sensitivity of the knee valgus moment to these parameters. Regardless, future work may benefit from examining associations between initial joint postures and valgus moment over a wider range of sidestepping movements, or in fact a variety of movement tasks.

\subsection{Implications for training}

In-line with recent research findings, we have chosen to focus on knee valgus moment because of its prospective link with ACL risk (Hewett et al., 2005). With this in 
mind, current results suggest that a reduction in valgus loading during sidestep stance can be achieved via modification of hip flexion-extension and internal-external rotation and knee varus-valgus positions prior to ground contact. Specifically "at-risk" individuals should be taught to land with less hip flexion and internal rotation and less knee valgus. These alterations appear particularly pertinent to females, whom elicit an increased valgus loading sensitivity to both hip internal rotation and knee valgus positions during sidestepping compared to their male counterparts. Steps must now be taken therefore, to determine precisely how, and perhaps if, these kinematic modifications can be successfully achieved via training. Determining the interaction between knee joint mechanics and ACL loading may also enable neuromuscular control strategies to be developed that accommodate rather than potentially exaggerate "high-risk" loading interactions. Finally, while specific neuromuscular changes may indeed reduce the risk of ACL injury during sidestepping via a valgus loading mechanism, their impact on sport-specific performance requirements remains unclear. Initial findings suggest that modification of "high-risk" lower limb movement patterns without performance detriment is possible for similar movements (Hewett et al., 1996, 1999; Myer et al., 2005). However, this relationship needs to be investigated further for various sports movements.

\section{Conclusions}

The current study examined the relationship between lower limb kinematics at initial contact during sidestepping and resultant peak stance phase valgus moment as a means of identifying potential associations between these factors and ACL injury risk in males and females. Based on the results of this study, we conclude the following:

1. Females exhibit increased normalized (mass $\times$ height) peak valgus moments during the stance phase of sidestepping compared to males.

2. Greater peak valgus moments occur during sidestep stance with concomitantly greater initial contact hip flexion, internal rotation and knee valgus positions.

3. Peak valgus moment during sidestepping is more sensitive to initial contact hip internal rotation and knee valgus excursions in women compared to men.

4. Improved hip neuromuscular control during sidestepping may reduce the likelihood of ACL injury via a valgus loading mechanism, particularly for females.

\section{Acknowledgement}

This work was supported by US National Institutes of Health (1 R01 AR47039).

\section{References}

Agel, J., Arendt, E.A., Bershadsky, B., 2005. Anterior cruciate ligament injury in national collegiate athletic association basketball and soccer. Am. J. Sports Med.

Arendt, E., Dick, R., 1995. Knee injury patterns among men and women in collegiate basketball and soccer. NCAA data and review of literature. Am. J. Sports Med. 23, 694-701.

Besier, T.F., Lloyd, D.G., Cochrane, J.L., Ackland, T.R., 2001. External loading of the knee joint during running and cutting maneuvers. Med. Sci. Sports Exer. 33, 1168-1175.

Besier, T.F., Lloyd, D.G., Ackland, T.R., 2003. Muscle activation strategies at the knee during running and cutting maneuvers. Med. Sci. Sports Exer. 35, 119-127.

Chappell, J.D., Yu, B., Kirkendall, D.T., Garrett, W.E., 2002. A comparison of knee kinetics between male and female recreational athletes in stop-jump tasks. Am. J. Sports Med. 30, 261-267.

Decker, M.J., Torry, M.R., Wyland, D.J., Sterett, W.I., Steadman, R.J., 2003. Gender differences in lower extremity kinematics, kinetics and energy absorption during landing. Clin. Biomech. 18, 662-669.

de Leva, P., 1996. Adjustments to Zatsiorsky-Seluyanov's segment inertia parameters. J. Biomech. 29, 1223-1230.

Ferber, R., Davis, I.M., Williams, D.S., 2003. Gender differences in lower extremity mechanics during running. Clin. Biomech. 18, 350357.

Frank, C.B., Jackson, D.W., 1997. The science of reconstruction of the anterior cruciate ligament. J. Bone Joint Surg. Am. 79, 1556-1576.

Griffin, L.Y., Agel, J., Albohm, M.J., Arendt, E.A., Dick, R.W., Garrett, W.E., Garrick, J.G., Hewett, T.E., Huston, L., Ireland, M.L., Johnson, R.J., Kibler, W.B., Lephart, S., Lewis, J.L., Lindenfeld, T.N., Mandelbaum, B.R., Marchak, P., Teitz, C.C., Wojtys, E.M., 2000. Noncontact anterior cruciate ligament injuries: risk factors and prevention strategies. J. Am. Acad. Orthop. Surg. 8, 141-150.

Grood, E.S., Suntay, W.J., 1983. A joint coordinate system for the clinical description of three-dimensional motions: application to the knee. J. Biomech. Eng. 105, 136-144.

Hewett, T.E., Stroupe, A.L., Nance, T.A., Noyes, F.R., 1996. Plyometric training in female athletes. Decreased impact forces and increased hamstring torques. Am. J. Sports Med. 24, 765-773.

Hewett, T.E., Lindenfeld, T.N., Riccobene, J.V., Noyes, F.R., 1999. The effect of neuromuscular training on the incidence of knee injury in female athletes. A prospective study. Am. J. Sports Med. 27, 699-706.

Hewett, T.E., Myer, G.D., Ford, K.R., Heidt Jr., R.S., Colosimo, A.J., McLean, S.G., van den Bogert, A.J., Paterno, M.V., Succop, P., 2005. Biomechanical measures of neuromuscular control and valgus loading of the knee predict anterior cruciate ligament injury risk in female athletes. Am. J. Sports Med.

Huston, L.J., Wojtys, E.M., 1996. Neuromuscular performance characteristics in elite female athletes. Am. J. Sports Med. 24, 427-436.

Hutchinson, M.R., Ireland, M.L., 1995. Knee injuries in female athletes. Sports Med. 19, 288-302.

Ireland, M.L., 2002. The female ACL: Why is it more prone to injury? Orthop. Clin. N. Am. 33, 637-651.

Ives, J.C., Kroll, W.P., Bultman, L.L., 1993. Rapid movement kinematic and electromyographic control characteristics in males and females. Res. Quart. Exer. Sport 64, 274-283.

Lephart, S.M., Abt, J.P., Ferris, C.M., 2002. Neuromuscular contributions to anterior cruciate ligament injuries in females. Curr. Opin. Rheumatol. 14, 168-173.

Lloyd, D.G., Buchanan, T.S., 2001. Strategies of muscular support of varus and valgus isometric loads at the human knee. J. Biomech. $34,1257-1267$ 
Maletius, W., Messner, K., 1999. Eighteen- to twenty-four-year followup after complete rupture of the anterior cruciate ligament. Am. J. Sports Med. 27, 711-717.

Malinzak, R.A., Colby, S.M., Kirkendall, D.T., Yu, B., Garrett, W.E., 2001. A comparison of knee joint motion patterns between men and women in selected athletic tasks. Clin. Biomech. 16, 438-445.

McLean, S.G., Su, A., van den Bogert, A.J., 2003. Development and validation of a 3-D model to predict knee joint loading during dynamic movement. J. Biomech. Eng. 125, 864-874.

McLean, S.G., Lipfert, S.W., Van Den Bogert, A.J., 2004a. Effect of gender and defensive opponent on the biomechanics of sidestep cutting. Med. Sci. Sports Exer. 36, 1008-1016.

McLean, S.G., Huang, X., Su, A., Van Den Bogert, A.J., 2004b. Sagittal plane biomechanics cannot injure the ACL during sidestep cutting. Clin. Biomech. 19, 828-838.

Myer, G.D., Ford, K.R., Palumbo, J.P., Hewett, T.E., 2005. Neuromuscular training improves performance and lower-extremity biomechanics in female athletes. J. Strength Cond. Res. 19, 51-60.

Myklebust, G., Engebretsen, L., Braekken, I.H., Skjolberg, A., Olsen, O.E., Bahr, R., 2003. Prevention of anterior cruciate ligament injuries in female team handball players: a prospective intervention study over three seasons. Clin. J. Sport Med. 13, 71-78.

Olsen, O.E., Myklebust, G., Engebretsen, L., Holme, I., Bahr, R., 2005. Exercises to prevent lower limb injuries in youth sports: cluster randomised controlled trial. BMJ 330, 449.
Rozzi, S.L., Lephart, S.M., Gear, W.S., Fu, F.H., 1999. Knee joint laxity and neuromuscular characteristics of male and female soccer and basketball players. Am. J. Sports Med. 27, 312-319.

Salci, Y., Kentel, B.B., Heycan, C., Akin, S., Korkusuz, F., 2004. Comparison of landing maneuvers between male and female college volleyball players. Clin. Biomech. (Bristol, Avon) 19, 622628.

Winter, D.A., 2005. Biomechanics and motor control of human movement, third ed. Wiley and Sons Publishers, New Jersey, USA.

Wojtys, E.M., Huston, L.J., Schock, H.J., Boylan, J.P., Ashton-Miller, J.A., 2003. Gender differences in muscular protection of the knee in torsion in size-matched athletes. J. Bone Joint Surg. Am. 85-A, 782-789.

Woltring, H.J., Huiskes, R., de Lange, A., Veldpaus, F.E., 1985. Finite centroid and helical axis estimation from noisy landmark measurements in the study of human joint kinematics. J. Biomech. 18, 379-389.

Zeller, B.L., McCrory, J.L., Kibler, W.B., Uhl, T.L., 2003. Differences in kinematics and electromyographic activity between men and women during the single-legged squat. Am. J. Sports Med. 31, 449456.

Zhang, L.Q., Xu, D., Wang, G., Hendrix, R.W., 2001. Muscle strength in knee varus and valgus. Med. Sci. Sports Exer. 33, 1194 1199 . 